\title{
Management of Intraoral Gunshot Injury - A Case Report
}

\author{
Goel $\mathbf{M}^{1}$, Puri $\mathrm{P}^{2}$, Agarwal $\mathrm{A}^{3}$, Kumar $\mathrm{A}^{4}$, Priya $\mathrm{K}^{5}$
}

\begin{abstract}
Oral and Maxillofacial gunshot injuries are usually lethal due to close proximity with the vital structures. The severity of injury varies according to the caliber of the weapon used and to the distance from which the patient is shot. A case of gunshot injury that was successfully managed by surgical exploration and removal of bullet from left maxillary antrum under local anesthesia is presented. The initial care of facial gunshot wounds strictly adheres to the basics of trauma resuscitation. Early and appropriate surgical management have proved to be influential on the final outcome and aesthetic result. Treatment of gunshot injuries should be planned and carried out carefully. It takes different stages and procedures to achieve the targeted treatment plan. Prevention and control of infection are important in the success of the treatment.
\end{abstract}

Keywords: Gunshot injury, Bullet, Maxillary antrum, Surgical exploration

${ }^{1}$ Associate Professor

Department Of Oral \& Maxillofacial Surgery PGIDS, University Of Health Sciences, Rohtak, Haryana, INDIA

${ }^{2}$ MDS, Senior Resident

Department Of Oral \& Maxillofacial Surgery PGIDS, University Of Health Sciences, Rohtak, Haryana, INDIA

${ }^{3}$ Postgraduate Student

Department Of Oral \& Maxillofacial Surgery PGIDS, University Of Health Sciences, Rohtak, Haryana, INDIA

${ }^{4}$ MDS, Demonstrator

Department of Pedodontics and Preventive Dentistry

PGIDS, University Of Health Sciences, Rohtak, Haryana, INDIA

${ }^{5}$ Postgraduate Student

Department Of Oral \& Maxillofacial Surgery PGIDS, University Of Health Sciences, Rohtak, Haryana, INDIA

\section{Contact Author}

Dr. Mahesh Goel drmaheshgoelos@gmail.com

J Oral Health Comm Dent 2014;8(1)58-61

\section{INTRODUCTION}

unshot injuries are on a rise in Toth developed and developing countries, the reason for this may be increased access to firearms. Gunshot injuries to the neck and maxillofacial region are associated with high morbidity and mortality due to the complex anatomy and presence of various vital structures in this region. Hollier et al (1) have stated that the Facial gunshot wounds can result in devastating functional and aesthetic consequences for patients. Depending on the type of firearm, the velocity of the projectile, the distance from which the patient is shot and tissue resistance are the factors that determine the severity of injury to the affected person $(1,2)$.

Early management of these patients must focus on the basics of resuscitation, with paramount attention given to the status of the airway. Bleeding from the injury and the subsequent swelling associated with it can significantly compromise the airway. Control of airway with either an endotracheal tube or tracheostomy should be considered early. Following this, hemodynamic resuscitation should be performed, if necessary, followed by thorough patient evaluation to rule out concomitant injuries (1).

Once the extent of damage has been assessed, an individual treatment plan can be established. Although it has been argued that gunshot wounds and the bony injuries resulting from them can frequently be managed nonoperatively (3), this argument is in direct contradiction to most of the more recently published experiences with facial fractures. It has been advocated that early operative repair of facial fractures resulting from blunt trauma and reconstitution of the soft tissue position is critical in obtaining an optimal result. This can be achieved with rigid internal fixation techniques. Failure to do so may result in displacement of the bone and/or scarring of the Soft tissue into the bone defect (4-6) further leading to residual deformity.

Surgical removal of the splinters will depend on the accessibility of the site where they are lodged. The maxillofacial surgeon should consider leaving splinters close to vital structures alone 


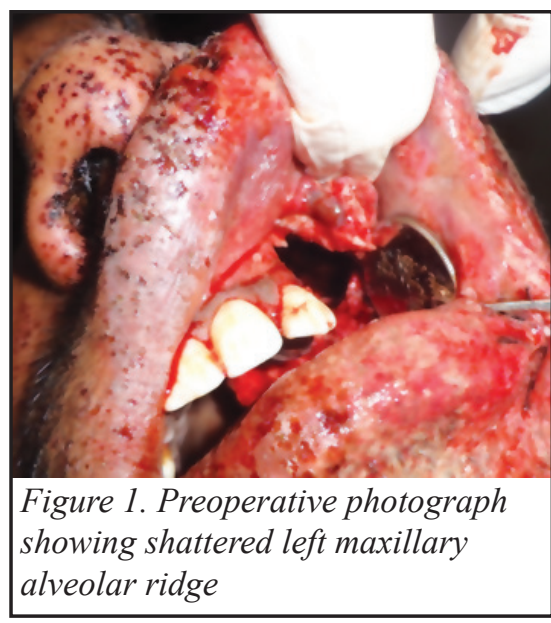

as the literature is still ambiguous on ammunition-related plumbism and neurotoxicity of copper (7). Here we are presenting a case of gunshot injury that was successfully managed by surgical exploration and removal of bullet from left maxillary antrum under local anesthesia.

\section{CASE REPORT}

A 32-year-old male reported to the casualty of PGIMS,Rohtak, approximately 4 hours after sustaining a bullet injury on the face. The history also revealed that the patient was shot with the hand gun at a very short distance from lower lip. The bullet entrance wound was in the lower lip. No possible exit wound for the bullet could be identified anywhere else on the head and neck region. The patient was fully conscious, oriented, well oriented to time, place and person. His vital signs were within normal limits. No neurological deficit was noted on examination. On intraoral examina-

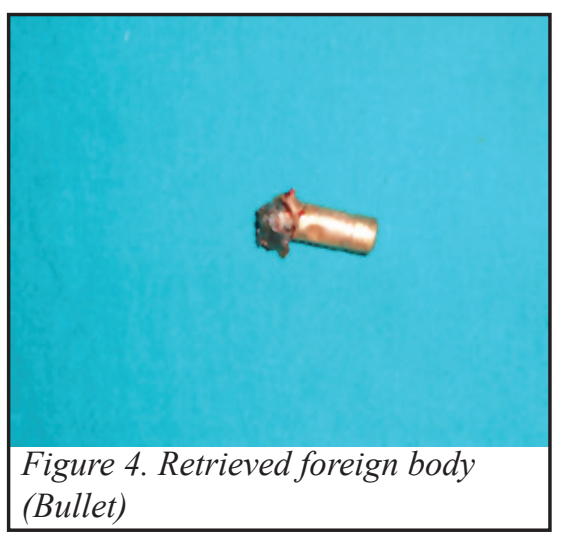

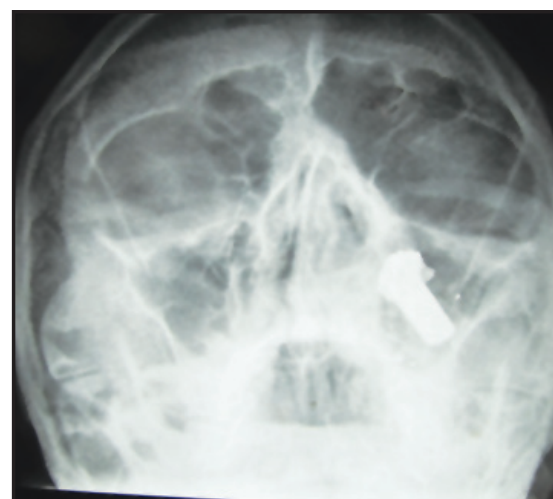

Figure 2. Pre operative paranasal sinus view showing foreign body in left maxillary antrum

tion upper left canine, first, second premolar, and first molar was missing. Left side maxillary bone was shattered. Left side face was edematous and black. Radiographic studies showed a foreign body in the left maxillary antrum. His blood investigations were within normal range.

Surgical site was prepared and surgical exploration of the left maxillary antrum was performed under local anesthesia. The foreign body was identified and removed. Wound was irrigated by copious amount of saline and minimally debrided. Foreign particles, any loose bony pieces and teeth fragmentation were removed. This was followed by sinus irrigation and wound

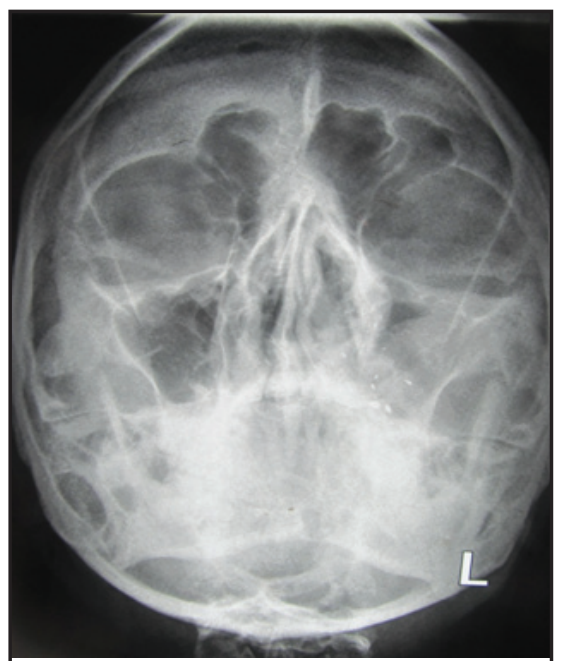

Figure 5. Postoperative paranasal sinus view showing retrieval of foreign body

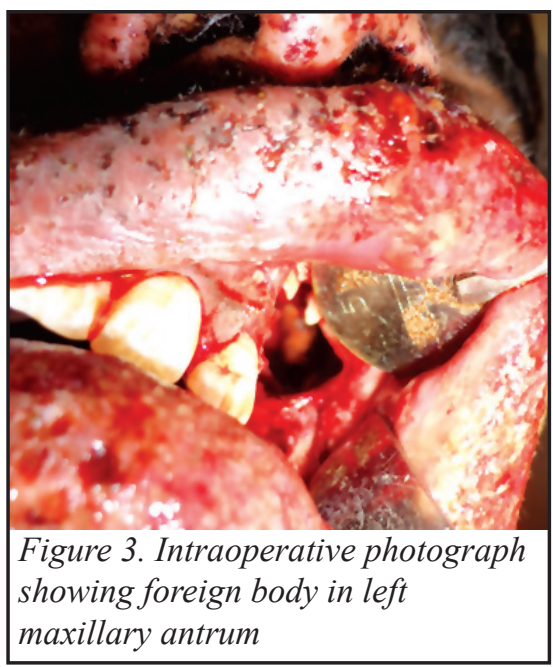

was closed. Also post operative antibiotics were given. Post operative period was uneventful. (Figure 1-6)

\section{DISCUSSION}

Gunshot wounds have been previously classified as penetrating, perforating, and avulsive (8). Penetrating wounds are caused when a projectile enters the victim but does not exit. Perforating wounds are caused when a projectile enters and exits the victim. Avulsive wounds are caused when the projectile enters the victim and exits with substantial loss of tissue. Unfortunately, these wound classifications do not coincide with current views of wounding capacity, views based on recent ballistics research. The most up-to date information suggests that velocity of impact has been overemphasized and that the most appropriate classification

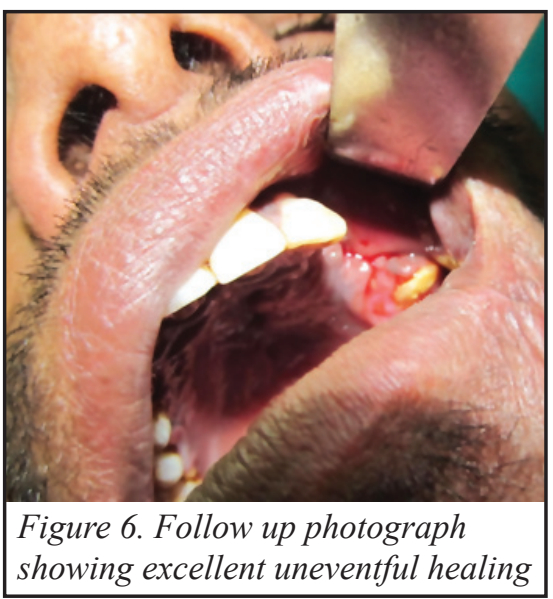


scheme involves either impact energy or the type of firearm involved (9).

A number of methods for estimating wounding capacity have been developed. Calculation of kinetic energy $(\mathrm{KE}=1 / 2 \mathrm{MV} 2)$ provides the most reliable estimate of wounding capacity. But even this method of estimating wounding capacity has been challenged (10). For contact or close-range injuries, the effect of the gas that is discharged under pressure into the wound should also be considered. This effect is complicated to estimate but is important for wound management because it increases wound contamination and tissue damage. The most common types of firearm used are handguns, rifles, and shotguns. Handguns fire lowcaliber projectiles (lead or lead alloy) at low velocity $(<2,000 \mathrm{ft} / \mathrm{s})$. Rifles fire low- to high-caliber projectiles at high velocity $(>2,000 \mathrm{ft} / \mathrm{s})$. A shotgun is a long gun that may fire a single pellet or hundreds of pellets at low velocity (11).

As the projectile enters the victim, the different layers of tissue react according to their specific properties. Injuries to the dermis include abrasion, impaction of particulate matter, and contusion. At closer ranges, burning and implantation of powder and residue may occur and may result in a tattoo. After the projectile passes through the skin, it next encounters muscle tissue, which is very elastic and may sustain deformation of as much as four times the diameter of the projectile. On a cellular level, the muscle along the pathway of the projectile becomes devitalized and necrotic.

As the projectile travels, it may also encounter other surrounding vital structures such as nerves and blood vessels. The injuries to neurovascular tissue are similar to injuries to muscle. Vessels may be ruptured, crushed, or sheared, and spasm may occur. These injuries may result in hemorrhage and in the formation of thrombi and hematoma. On a cellular level, damage occurs to all three layers of the vessel wall (12). Sensory and motor nerves may be damaged. When sensory nerves stretch, anesthesia and paraesthesia result; when motor nerves stretch, conduction deficit, and loss of function result.

Injury to bony tissue differs from injury to soft tissues. The minimal projectile velocity required for bone fracture is $65 \mathrm{~m} / \mathrm{s}$. Bone is very inelastic; therefore, the type of injury that occurs depends on the type of bone encountered by the projectile. Injury to cancellous bone usually results in a defect of the drill-hole type. Injury to cortical bone or teeth usually results in shattering. The resulting fragments may act as secondary projectiles and may pose an aspiration risk (13).

The first procedure in definitive maxillofacial management of a gunshot injury is to irrigate the wound with normal saline. Irrigation debrides any necrotic tissue, removes foreign bodies, and brings the contaminants to nonpathogenic concentrations. Simple cutaneous wounds may be cleansed and dressed with bacitracin or sulfadiazine cream $1 \%$. Shattered bone and teeth along with debris should be removed under copious irrigation. Injuries resulting in active hemorrhage should be explored and repaired at the earliest. At the time of hemorrhage control, obvious nerve damage should also be repaired. Fractures should be treated with open reduction and internal fixation, but such treatment may be a formidable task if there is gross fragmentation or if the surgeon has minimal experience. In such cases, closed reduction and intermaxillary fixation, although not optimal, is acceptable treatment. Soft tissues should be closed after osseous injuries have been managed.

In the present case patient was shot at point blank range near the lower lip pointing towards upper left alveolar ridge. There was shattering of alveolar ridge from left maxillary canine to distal to first molar giving an open sky view to left maxillary antrum. On examination left maxillary antrum was found clear except in the area of confluence of upper lateral wall of nose and frontal process of maxilla where seems to be embedded a foreign body. Patient escaped injury to any vital structure. With good illumination and fine suction tip, the foreign body was removed after surgical exploration. The wound was debrided, irrigated and closed. Postoperative wound healing was uneventful.

\section{CONCLUSION}

Gunshot wounds in oral and maxillofacial region often present with frightful deformity. But prompt and proper emergency management, homodynamic resuscitation, airway management followed by proper evaluation of primary and concomitant injuries with its management definitely improve the outcome. Prevention and control of infection are important in the outcome of the treatment success.

\section{REFERENCES}

1. Hollier L, Grantcharova EP, Kattash M. Facial gunshot wounds: a 4-year experience. J Oral Maxillofac Surg 2001:59:277-82.

2. Lee D, Nash M, Turk J, Har-EI G. Lowvelocity gunshot wounds to the paranasal sinuses. Otolaryngol Head Neck Surg 1997; 116:372-78.

3. Finn RA. Treatment of comminuted mandibular fractures by closed reduction. J Oral Maxillofac Surg 1996;54:320.

4. Motamedi MHK, Behnia H. Experience with regioinal flaps in the comprehensive treatment of maxillofacial softtissue injuries in warfare victims. $J$ Craniomaxillofac Surg 1999;27:256.

5. Behnia H, Motamedi MHK. Reconstruction and rehabilitation of short-range, highvelocity gunshot injury to the lower face. J Craniomaxillofac Surg 1997;25:220.

6. Osborne TE, Bays RA. Pathophysiology and management of gunshot wounds to the face, in Fonseca RJ, Walker RV (eds): Oral and Maxillofacial Trauma, vol 2. Philadelphia, PA, Saunders, 1991, pp 672-79.

7. McQuiter JI, Rothenberg SJ, Dinkins GA, Manalo M, Kondrashov V, Todd AC. The effect of retained bullets on body lead burden. J Trauma 2001;50:892-99. 
8. Kelly JF. Management of War Injuries to the Jaws and Related Structures. Washington, DC, US Government Printing Office 1977; p36.

9. Fackler ML. Civilian gunshot wounds and ballistics: Dispelling the myths. Emerg Med Clin North Am 1998;16:17.

10. Lindsey $D$. The idolatry of velocity, or lies, damn lies, and ballistics. J Trauma 1980;20:1068.

11. National Rifle Association of America: NRA Firearms Fact Book (ed 3). Washington, DC, National Rifle Association Publications 1989.

12. Tan YH, Zhou SX, Liu YQ, et al. Smallvessel pathology and anastomosis following maxillofacial firearm wounds: An experimental study. J Oral Maxillofac Surg 1991;49:348.

13. Oehmichen M, Meissner C, Konig HG. Brain injury after gunshot wounding: Morphometric analysis of cell destruction caused by temporary cavitation. J Neurotrauma 2000;17:155. 